\title{
Physiological performance and cardiac function in female ironman- triathletes
}

\author{
Roman Leischik, Spelsberg N., Littwitz H., Dworrak B. \\ Department of Cardiology, Section Prevention and Sports Medicine, Faculty of Health, School of Medicine, Witten/Herdecke University, \\ Witten, Germany
}

\section{Email address:}

info@dr-leischik.de (R. Leischik)

\section{To cite this article:}

Roman Leischik, Spelsberg N., Littwitz H., Dworrak B. Physiological Performance and Cardiac Function in Female Ironman- Triathletes. American Journal of Sports Science. Vol. 2, No. 2, 2014, pp. 41-47. doi: 10.11648/j.ajss.20140202.16

\begin{abstract}
Background: Data about physiological performance of female ironman-triathletes are rare. However, some papers reported endurance sport may cause damage of the right or left ventricle even in females. Aim: The goal of this study was to assess prospectively the right/left ventricular function and physiological performance in female ironman-athletes (middle- and long-distance). Methods: 33 female healthy triathletes were examined using spiroergometry and echocardiography. Inclusion criterion was participation in at least one middle distance triathlon. Results: The triathletes achieved the following results: $\mathrm{VO}_{2} \max 52.8 \pm 5.7 \mathrm{ml} / \mathrm{min} / \mathrm{kg}$, Wmax $264.0 \pm 26.1$, VAT (aerobic threshold) VO2 $38.5 \pm$ $7.9 \mathrm{ml} / \mathrm{min} / \mathrm{kg}, 193.0 \pm 48.4 \mathrm{Watt}$. In respect of echocardiographic readings LVEDD (left ventricular end-diastolic diameter) was $4.4 \pm 0.3 \mathrm{~cm}$ and the left ventricular muscle mass $(\mathrm{LVM})$ was $145.9 \pm 31.3 \mathrm{~g}\left(\mathrm{LVM}\right.$ index $\left.85.8 \mathrm{~g} / \mathrm{m}^{2} \pm 18.7\right)$. Conclusions: The performance date of female triathletes can be used as training goals for leisure female triathletes, when middle or long distances in triathlon competitions should be finished. In respect of echocardiographic parameters a right or left ventricular dysfunction could not be found despite of long times of training and finishing of long distance competitions $(5.4 \pm 2.8$ years triathlon competitions non-elite and $7.6 \pm 5.8$ years elite athletes).
\end{abstract}

Keywords: Triathlon, Ironman, Cardiac Fatigue, Female Athletes

\section{Introduction}

Participation in triathlon competitions has increased in the recent years. At the end of 1999, membership (annual and one-day) stood at 127,824 . Those numbers had more than doubled to 262,703 by 2005 , and USA triathlon continued to experience double-digit annual growth through 2007, when it reached 336,356 members [1]. Performance and echocardiographic data of average female triathletes participating in middle and long distance triathlons are rare. Some papers presumed pathological right ventricular remodelling [2] and "left ventricular fatigue" after middle or long distance triathlons [3]. Cases of sudden death during triathlons were reported [4].

Triathlon is an endurance sport specifically performed in middle and long distance formats (e.g. middle/long distance ironman: 1.9/3.8km swim, 90/180 km bicycle ride and 21.1/42.2 km run), mainly under aerobic conditions [5]. It is particularly important for triathletes to perform at sub-maximal levels over a long period to avoid reaching a state of exhaustion [6]. Elite athletes require 4 to 4.5 hours to complete middle distance events and 8 to 10 hours for long distance events. Amateur athletes typically take periods of 5 to 6.5 hours for middle distance events and 10 to 16 hours for long distance events. Such long periods of stress require both the amateur athletes as well as the top athletes to be adequately trained and to have sufficient aerobic capacity $[5,7]$. A number of studies with small cohorts have been published in respect of spiroergometric data [8-13]. Echocardiographic data of triathletes (retrospective analysis, mainly males) have also been reported [14]. All these studies raise the question which types of cardiac changes in function or structure can be found in female triathletes. Further questions are:

- Which performance data can be achieved by mainstream female triathletes participating in middle and full distance competitions?

- $\quad$ Are there signs of cardiac dysfunction (cardiac fatigue) in middle and long distance female triathletes? 


\section{Patients and Methods}

33 female triathletes have been examined by echocardiography and spiroergometry. The echocardiograph produced by General Electric, model Vivid 7 was used for the examinations. The Ergobike 8I produced by Daum and the Metalizer 3B produced by Cortex were used for spiroergometric examination. In order to compare the data from elite triathletes with those of non-elite triathletes, athletes were divided into two groups according to the aerobic capacity (relative $\mathrm{VmaxO}_{2} / \mathrm{min} / \mathrm{kg}$ at the aerobic threshold).

All triathletes were examined during one day using at first echocardiography and later spiroergometry.

\subsection{Echocardiography}

The echocardiographic analysis and estimation of left ventricular mass (LVM) was conducted according to general recommendations (20). The formula recommended by the American Society of Echocardiography (ASE) was used to calculate the muscle mass. EDV and ESV was determined monoplane (unclear meaning) after the modified Simpson method.

\subsection{Spiroergometry}

Spiroergometry was performed in the following way: The stress test was conducted in stages after successful gas and volume calibration: $50 \mathrm{~W}$ for 3 minutes, $100 \mathrm{~W}$ for a further 3 minutes and thereafter increased by another 30 Watt every 3 minutes. The test ended when the subject could no longer maintain the predefined RPM of 90 or if the subject was exhausted.

Spiroergometric analyses were conducted according to literature: VAT was determined as first non-linear increase of the ventilatory equivalent for oxygen without simultaneous increase of the ventilatory equivalent for $\mathrm{CO}_{2}$ and RCP as simultaneous non-linear increase of both ventilatory equivalents according to recommendations (21). $\mathrm{VO}_{2} \max$ was registered as the highest average value of oxygen absorption over 30 seconds.

\subsection{Statistics}

The entire statistical analysis plan was designed as follows: Stata/IC 13.1 for Windows was used for data preparation and statistical analysis. The Mann-Whitney-U-Test was used for comparing the groups.

\section{Results}

\subsection{Anthropometry}

Anthropometric data and general echocardiographic parameters of triathletes are listed in table 1. Systolic blood pressure values at rest were similar: $117.4 \pm 8.6 \mathrm{mmHg}$ vs. $121.9 \pm 8.4 \mathrm{mmHg}$ (n.s.) in females with $\mathrm{LVM}>95 \mathrm{~g} / \mathrm{m}^{2} \mathrm{vs}$. $\mathrm{LVM}<95 \mathrm{~g} / \mathrm{m}^{2}$.
Table 1. Anthropometry and echocardiographic parameters.

\begin{tabular}{|c|c|c|c|c|}
\hline & $\mathbf{n}$ & Mv & Sd & Min-Max \\
\hline Age (years) & 33 & 34,3 & 8,1 & $20.0-53.0$ \\
\hline Weight (kg) & 33 & 61,5 & 7,8 & $48.7-79.6$ \\
\hline Size $(\mathrm{cm})$ & 33 & 168,8 & 6,4 & $158.0-180.0$ \\
\hline BMI $\left(\mathrm{kg} / \mathrm{m}^{2}\right)$ & 33 & 21,6 & 2,28 & $18.3-26.6$ \\
\hline $\operatorname{BSA}\left(\mathrm{m}^{2}\right)$ & 33 & 1,7 & 0,13 & $1.48-1.97$ \\
\hline \%bodyfat & 33 & 22,8 & 4,7 & $12.7-32.6$ \\
\hline Aorta $(\mathrm{cm})$ & 33 & 2,47 & 0,24 & $2.00-2.9$ \\
\hline Leftatrium $(\mathrm{cm})$ & 33 & 2,35 & 0,25 & $1.90-2.9$ \\
\hline $\operatorname{LAESV}^{*}(\mathrm{ml})$ & 33 & 27,4 & 9,3 & $14.0-55.0$ \\
\hline IVS diastolic $(\mathrm{cm})$ & 33 & 1,02 & 0,17 & $0.70-1.50$ \\
\hline IVS systolic (cm) & 33 & 1,44 & 0,22 & $0.90-1.90$ \\
\hline PWD diastolic $(\mathrm{cm})$ & 33 & 1,02 & 0,16 & $0.80-1.40$ \\
\hline PWD systolic (cm) & 33 & 1,48 & 0,2 & $1.20-2.00$ \\
\hline Relative Wallthickness & 33 & 0,47 & 0,09 & $0.33-0.76$ \\
\hline LVEDD $(\mathrm{cm})$ & 33 & 4,4 & 0,32 & $3.7-5.0$ \\
\hline $\operatorname{LVESD}(\mathrm{cm})$ & 33 & 2,9 & 0,27 & $2.40-3.4$ \\
\hline $\operatorname{LVM}(\mathrm{g})$ & 33 & 145,9 & 31,3 & $86.8-212.6$ \\
\hline $\operatorname{LVM}\left(\mathrm{g} / \mathrm{m}^{2}\right)$ & 33 & 85,8 & 18,7 & $58.3-134.6$ \\
\hline LVEDV (ml) & 33 & 105 & 17,8 & $79.0-148.0$ \\
\hline LVESV (ml) & 33 & 38,9 & 7,1 & $28.0-52.0$ \\
\hline $\mathrm{SV}(\mathrm{ml})$ & 33 & 66,1 & 11,3 & $48.0-98.0$ \\
\hline $\mathrm{EF}(\%)$ & 33 & 63 & 2,7 & $57.0-68.0$ \\
\hline LVOT Vmax m/s & 32 & 0,86 & 0,13 & $0.63-1.17$ \\
\hline $\operatorname{MV} \operatorname{E} \operatorname{Max}(\mathrm{m} / \mathrm{s})$ & 33 & 0,56 & 0,12 & $0.33-0.98$ \\
\hline MV A Max (m/s) & 33 & 0,38 & 0,09 & $0.26-0.72$ \\
\hline MV E/A Ratio & 33 & 1,54 & 0,34 & $0.85-2.27$ \\
\hline RV parastenal & 33 & 2,4 & 0,18 & $2.10-2.9$ \\
\hline $\mathrm{RV} \mathrm{AFC \%}$ & 33 & 32,2 & 2,8 & $24.6-38.8$ \\
\hline
\end{tabular}

Legend: $\mathrm{n}=$ number, $\mathrm{Mv}=$ mean value, $\mathrm{Sd}=$ standard deviation, $\mathrm{Min}=$ minimum, $\mathrm{Max}=$ maximum* $=$ of the Mann-Whitney-U-Test, BMI = body mass index, BSA = body surface area, LA = left atrial diameter, LAESV $=$ left atrial endsystolic volume, IVS $=$ intervent. septum, LVPWT $=$ LV posterior wall thickness, RWT $=$ relative wall thickness, LVEDD $=\mathrm{LV}$ enddiastolic diameter, LVEDV = LV enddiastolic volume, $=$ diastolic, $\mathrm{s}=$ systolic, RV FC\%: right ventricular area fractional change.

The first best 15 females were chosen as elite, according to the aerobic capacity (relative $\mathrm{VO}_{2} \mathrm{max} \mathrm{ml} / \mathrm{min} / \mathrm{kg}$ at the aerobic threshold). In this group, there was a world ironman champion (age group), a national champion, and participants of the $1^{\text {st }}$ national triathlon league.

The mean time of participation in triathlon for elite athletes was $7.6 \pm 5,8$ and for non-elite athletes $5.4 \pm 2.8(\mathrm{p}=0.456)$ (table 2). There were no significant differences according to anthropometric data between elite and non-elite athletes, especially with regard to weight or \%body fat value (table 2). Only heart rate at rest was significant lower and diastolic wall thickness was minimally increased in elite-females.

Table 2. Differences between Elite and Non-Elite female triathletes.

\begin{tabular}{llllll}
\hline & p-value & \multicolumn{2}{c}{ Elite-Females } & \multicolumn{2}{c}{ Non-Elite females } \\
& & Mv & SD & Mv & SD \\
\hline Age (years) & 0.786 & 33.6 & 9.2 & 34.8 & 7.2 \\
weight $(\mathrm{kg})$ & 0.759 & 60.9 & 6.8 & 62.0 & 8.6 \\
BMI $\left(\mathrm{kg} / \mathrm{m}^{2}\right)$ & 0.247 & 21.1 & 2.2 & 22.0 & 2.3 \\
BSA & 0.986 & 1.69 & 0.11 & 1.7 & 0.14 \\
\% bodyfat & 0.366 & 22.1 & 4.3 & 23.4 & 5.0 \\
distance swimm/week & 0.185 & 8.5 & 3.9 & 6.1 & 3.1 \\
distance bike/week/km & 0.971 & 173.0 & 67.7 & 164.7 & 75.2 \\
distance run/week/km & 0.085 & 55.3 & 9.1 & 48.3 & 16.6 \\
HR & 0.002 & 160.6 & 14.5 & 138.6 & 19.9 \\
\hline
\end{tabular}




\begin{tabular}{llllll}
\hline & p-value & \multicolumn{2}{c}{ Elite-Females } & \multicolumn{2}{c}{ Non-Elite females } \\
& & Mv & SD & Mv & SD \\
\hline IVSdiastolic cm & 0.024 & 1.09 & 0.18 & 0.95 & 0.12 \\
LVPWd cm & 0.034 & 1.09 & 0.18 & 0.97 & 0.13 \\
IVSsystolic cm & 0.042 & 1.53 & 0.21 & 1.37 & 0.21 \\
EF (Teich) \% & 0.069 & 63.7 & 3.7 & 61.2 & 3.9 \\
LVs Mass Index g/m & 0.159 & 92.3 & 20.8 & 80.5 & 15.4 \\
abs. VO 2 max & 0.006 & 3,4 & 0,3 & 3,1 & 0,3 \\
rel. VO V2max $_{\text {rel. VO2 }}^{\text {AT }}$ & 0.004 & 56.1 & 5.7 & 50.1 & 4.1 \\
ren & 0.000 & 45.5 & 5.4 & 32.7 & 3.8 \\
\hline
\end{tabular}

\subsection{Echocardiography}

One triathlete showed aortic valve insufficiency, which can be described as mild. All other triathletes showed normal results in respect of their cardiac valves.
There were no significant differences between elite and amateur athletes in respect of echocardiographic parameters.

In the study population concentric changes of the left ventricle characterised the morphology. 17 females $(51 \%)$ displayed concentric remodelling and $6(18 \%)$ concentric hypertrophy. Normal LV-morphology was found in 9 (27\%) females. Eccentric hypertrophy was rare: 1 (3\%) participants of the study.

The classification into the types of hypertrophy followed the criteria of Lang et al. [15]. Right ventricular remodelling or other pathological findings in right ventricle were not found. Left and right ventricular function was excellent in all female triathlete even if they train a lot (Table 3).

Table 3. Training characteristics for Elite-females and Non-Elite females.

\begin{tabular}{llllllll}
\hline & \multicolumn{2}{c}{ Elite Females } & \multicolumn{2}{c}{ Non-Elite Females } \\
& n & Mv & Sd & n & Mv & Sd & P values* \\
\hline Swimming time hrs/ week & 15 & 4.0 & 1.2 & 18 & 3.2 & 1.1 \\
Swimming dist. km / week & 15 & 8.5 & 3.9 & 18 & 6.6 & 3.1 \\
Biking time hrs/ week & 15 & 6.7 & 2.3 & 18 & 6.5 & 1.9 \\
Biking dist. km / week & 15 & 173 & 67.7 & 18 & 165 & 75.2 \\
Running time hrs/ week & 15 & 5.5 & 1.3 & 18 & 4.8 & 1.4 \\
Running dist. km / week & 15 & 55.3 & 9.1 & 18 & 48.3 & 1.07 \\
Training time hrs/ week & 15 & 16.5 & 3.2 & 18 & 14.7 & 0.971 \\
Triathlete since years & 15 & 7.6 & 5.8 & 18 & 5.4 & 0.116 \\
\hline
\end{tabular}

$\mathrm{n}=$ number, $\mathrm{Mv}=$ mean value, $\mathrm{Sd}=$ standard deviation, $*=\mathrm{p}$ value of the Mann-Whitney-U-Test

\subsection{Spiroergometry}

Average maximal relative $\mathrm{VO}_{2}$ max uptake was $52.8 \pm$ $5.7 \mathrm{ml} / \mathrm{min} / \mathrm{kg}$, at the aerobic threshold (VAT) $38.5 \pm 7.9$ $\mathrm{ml} / \mathrm{min} / \mathrm{kg}$.

Oxygen absorption, ergometer performance and heart rate at VAT, at the anaerobic threshold (RCP) and at peak capacity are shown in table 4 , according to the performance data.

Tab 4. Heart frequency, oxygen uptake and power output depending on performance.

\begin{tabular}{|c|c|c|c|c|c|c|c|}
\hline & \multicolumn{3}{|c|}{ Elite females } & \multicolumn{4}{|c|}{ Non-elite females } \\
\hline & $\mathbf{n}$ & Mv & Sd & $\mathbf{n}$ & Mv & Sd & P values * \\
\hline \multicolumn{8}{|c|}{ VAT (aerobic threshold) } \\
\hline HR & 15 & 160.6 & 14.5 & 18 & 138.6 & 19.9 & 0.002 \\
\hline $\mathrm{aVO} 2$ & 15 & 2.76 & 0.35 & 18 & 1.99 & 0.46 & 0.000 \\
\hline $\mathrm{rVO} 2$ & 15 & 45.5 & 5.4 & 18 & 32.7 & 3.8 & 0.000 \\
\hline$\% \mathrm{VO} 2 \max$ & 15 & 81.2 & 7.0 & 18 & 64.4 & 12.9 & 0.000 \\
\hline $\mathrm{W}$ & 15 & 230.0 & 24.5 & 18 & 162.2 & 41.4 & 0.000 \\
\hline \multicolumn{8}{|c|}{ RCP (anaerobic threshold) } \\
\hline HR & 15 & 169.8 & 12.6 & 18 & 152.3 & 21.0 & 0.016 \\
\hline $\mathrm{aVO} 2$ & 15 & 3.06 & 0.28 & 18 & 2.33 & 0.56 & 0.001 \\
\hline rVO2 & 15 & 46.8 & 14.9 & 18 & 37.4 & 6.3 & 0.000 \\
\hline$\% \mathrm{VO} 2 \max$ & 15 & 91.7 & 6.7 & 18 & 75.3 & 14.7 & 0.001 \\
\hline $\mathrm{W}$ & 15 & 252.5 & 23.8 & 18 & 195.0 & 44.0 & 0.000 \\
\hline \multicolumn{8}{|c|}{ Peak capacity } \\
\hline HR & 15 & 179.7 & 10.0 & 18 & 179.8 & 7.6 & 0.971 \\
\hline aVO2max & 15 & 3.4 & 0.3 & 18 & 3.1 & 0.3 & 0.006 \\
\hline rVO2max & 15 & 56.1 & 5.7 & 18 & 50.1 & 4.1 & 0.004 \\
\hline Wmax & 15 & 274.0 & 32.5 & 18 & 256.7 & 16.4 & 0.097 \\
\hline
\end{tabular}

$\mathrm{n}=$ number; $\mathrm{Mv}=$ Mean value; $\mathrm{Sd}=$ standard deviation, $\mathrm{aVO} 2=$ absolute $\mathrm{VO} 2$ in $\mathrm{L} / \mathrm{min}, \mathrm{rVO} 2=$ relative $\mathrm{VO} 2$ in $\mathrm{ml} / \mathrm{min} / \mathrm{kg}, *=$ of the Mann-Whitney-U-Test, $\mathrm{HR}=$ heart rate, $\mathrm{W}=$ power output.
Non-elite female triathletes showed maximal performance values comparable to values of recreational female triathletes ( 50.1 vs. $48.2 \mathrm{ml} / \mathrm{min} / \mathrm{kg}$ ) described by Butts et al. [11]. As expected, the relative oxygen uptake was higher in elite females (abs. and rel. $\mathrm{VO}_{2} \max$ ), according to the aerobic capacity. The performance data of our long-distance triathlon collective showed lower $\mathrm{VO}_{2}$ max values as compared with data of elite female triathletes from Olympic distance $(61.3 \mathrm{ml} / \mathrm{min} / \mathrm{kg}$ vs. 56.1$)$ [13]. Female triathletes from Olympic distance can obtain even higher values in the range of $65.6 \mathrm{ml} / \mathrm{min} / \mathrm{kg}$ from treadmill ergometer test [16].

\section{Discussion}

\subsection{General}

Most studies of triathlon have focused to male triathletes, this study describes so far the largest cohort of long distance female triathletes using echocardiography and performance data.

\subsection{Cardiac Adaptation and Left Ventricular Hypertrophy}

The specific endurance training of triathletes leads to physiological changes of the performance parameters [5] and also results in changes of cardiac function or its architecture [17]. This adaptation is linked to the nature and magnitude of the physical exercise [18]. The physiological adaptation is a "harmonic increase in size" of a healthy heart caused by physical activity [19]. The term "athlete's heart" [18] is 
known since 1899 [20] and has been a topic of medical and scientific interest since the late nineteenth century [18].

Female athletes have generally less frequently a LVM $>220$ g. LVM of female endurance athletes was described with $175 \pm 38 \mathrm{~g}$ [21]. There was a mixed analysis of cyclists, rowers, runners, swimmers and roller skaters.

In our study we found a smaller LVM of $145.9 \pm 31.3$. Concentric hypertrophy in triathletes has already been described [14].

Douglas et al. [22] published a comparison of 36 male triathletes comprising 17 normal control and 15 high pressure subjects. The authors suggested that triathletes undergo cardiac adaptations like under increased arterial pressure conditions and described a RWD of 0.41. In these triathletes the left ventricular muscle mass was correlated positively with the increased systolic blood pressure during exercise [22]. This problem occurs more often in male triathletes. The present study showed no significant relationship of myocardial thickening to blood pressure values. Hypertension in female triathletes is rare. Neither resulted a correlation between muscle mass and blood pressure values at the aerobic threshold, nor a correlation between increased blood pressure values at rest or at peak capacity. The females of the present study showed no signs of exercise-induced arterial hypertension.

Douglas at al. [14] examined the occurrence of concentric hypertrophy in a retrospective study. Echocardiographic results of 168 male and 67 female Hawaii Ironman triathletes were collected retrospectively and examined from 1985 to 1995. However, in this study concentric hypertrophy was observed only rarely (in $2 \%$ of the triathletes) and eccentric hypertrophy in $7 \%$ of the triathletes.

In other large cohorts of different athletes concentric hypertrophy was also described rarely [23]. However, the meta-analysis described by Pellicia et al. [23] included athletes from 25 different disciplines, so that the results cannot be compared to triathletes. 15 female cyclists of this meta-analysis demonstrated a LVM Index $\mathrm{g} / \mathrm{m}^{2}$ of $115 \pm 23$.

Cardiovascular adaptations to exercise have been systematically defined and differ depending to the type of conditioning endurance training. Cycling and rowing have the most effects on cavity size and wall thickness. Strength trained athletes showed the highest increase in wall thickness [24].

The main difference between triathletes and cyclist is that triathletes train not only under cycling, but also under running conditions; cycle racing includes more components of strength training. The functional changes of cardiac structures for triathletes resemble the changes in runners [25].

Even though an enlarged atrium should be characteristic for endurance athletes [17], the present study did not show enlarged atria in female triathletes. Highly trained cycle racers however showed an enlarged atrium, which was even larger in older cycle racers than in younger subjects [26].

The systolic and diastolic function in our study was not influenced. The diastolic function in our cohort is not materially impaired.

Sudden cardiac death is more likely in male athletes. [27]. The different causes of sudden cardiac death in athletes were reported: silent coronary disease [28], hypertrophic cardiomyopathy [29] and arrhythmogenic right ventricular cardiomyopathy [30] (table 5).

Table 5. Distribution of cardiovascular causes of sudden death in young athletes $\quad<12-35$ Years in \%.

\begin{tabular}{|c|c|c|c|c|}
\hline & Maron 2007 & Corrado 2003 & Sollberg 2010 & Marijon 2011 \\
\hline Aorticrupture & 2,2 & 1,8 & 4,3 & 2 \\
\hline Aorticstenosis/cong. HD & 1,8 & & 4,3 & 6 \\
\hline ARVC & 4 & 22 & & 4 \\
\hline Channelpathies (QT, WPW) & 3 & 1,8 & 8,7 & 12 \\
\hline Coronaryarteryanomalies & 24 & 11 & 3,3 & \\
\hline Coronarydisease & 3 & 18 & 48 & 6 \\
\hline Dilatative CM & 2 & 1,8 & & 4 \\
\hline Hypertrophic CM & 36 & 1,8 & 4,3 & 10 \\
\hline MVP & 4 & 7,3 & & 2 \\
\hline Myocarditis & 5,4 & 9 & 22 & 4 \\
\hline Possible HCM & 11,3 & & & 4 \\
\hline Riva musclebridge & 2,2 & 3,6 & & 2 \\
\hline \multirow[t]{2}{*}{ Unclear } & & 1,8 & & 36 \\
\hline & $\mathrm{n}=1049$ & $\mathrm{n}=55$ & $\mathrm{n}=22$ & $\mathrm{n}=50$ \\
\hline
\end{tabular}

\subsection{Physiological Performance}

An important prerequisite of successful participation in the middle and long distance of triathlon is a sufficient aerobic capacity. It also appears that this is essential to avoid possible damage due to long time endurance training [3]. Well trained endurance athletes do not suffer significant long-term damage [3] even athletes can exhibit momentary "cardiac fatigue" $[3,31]$.

The female triathletes examined in the present study showed no signs of pathological right ventricular remodelling or signs of left ventricular dysfunction. The performance data for amateur athletes identified by this study should be assumed as guide values for athletes participating 
in middle and long distance triathlons.

In the present study female athletes showed a $\mathrm{VO}_{2}$ max of 52.8 $\pm 5.7 \mathrm{ml} / \mathrm{min} / \mathrm{kg}$, the $\mathrm{VO}_{2}$ uptake at the aerobic threshold was $38.5 \pm 7.9 \mathrm{ml} / \mathrm{min} / \mathrm{kg}$. This data match with published data of smaller studies. We could not find any value for $\mathrm{VO}_{2}$ uptake at the aerobic threshold for female triathletes.

The maximum oxygen absorption in the previously published studies had a range of 48.2 up to $61.6 \mathrm{ml} / \mathrm{min} / \mathrm{kg}$ body weight amongst different groups that have been examined.

In contrast, in studies of groups with, for example, five world class athletes [13] results turn out higher. However, it can be postulated that a $\mathrm{VO}_{2} \max$ above $55 \mathrm{ml} / \mathrm{min} / \mathrm{kg}$ body weight is a good marker for successful participation in an Ironman competition, both in middle and long distance events. The oxygen absorption at the aerobic threshold should be above $35 \mathrm{ml} / \mathrm{min} / \mathrm{kg}$ body weight for females. In the present study, the examinations always took place using ergometric peak capacity by bicycle; so treadmill data can differ depending on the athletes" background [32]. Bunc et al. [33] proposes $\mathrm{VO}_{2} \mathrm{max}$ values for young Olympic triathletes - males an average of above $65 \mathrm{ml} / \mathrm{min} / \mathrm{kg}$ and females above 60 $\mathrm{ml} / \mathrm{min} / \mathrm{kg}$. This pertains to elite triathletes. In smaller studies $\mathrm{VO}_{2} \max$ values for female athletes [9] were averaged at $57.5 \mathrm{ml} / \mathrm{min} / \mathrm{kg}$.

Comparing the performance values of elite and amateur female athletes in the present study, a significant difference can be observed as expected: relative $\mathrm{VO}_{2} \max \quad 56.1 \pm 5.7$ vs. $50.1 \pm 4 \mathrm{ml} / \mathrm{min} / \mathrm{kg}$ and $\mathrm{VO}_{2}$ for VAT $45.5 \pm 5.4 \mathrm{vs}$. $32.7 \pm 3.8 \mathrm{ml} / \mathrm{min} / \mathrm{kg}$.

\section{Limitations and Future Directions}

The cross-sectional design of this study does not allow a certain decision about the lack of exercise-induced cardiac fatigue in female triathletes. Although our data suggest normal right and left ventricular function, confirmatory longitudinal work is necessary.

The results of this study support the subjective impression of daily practice and engagement in sports medicine since 15 years that female athletes suffer less frequently from negative-cardiac remodelling as discussed by different authors $[31,34,35]$.

\section{Summary}

The data of the present study on German female triathletes participating in middle and long distance events allow the practical use of this data as a routine part of everyday sports medicine and in classifying the efficiency of performance diagnostic centres. We favour as training goals for successful finishing a middle or long distance triathlon a minimum of aerobic capacity of $35 \mathrm{ml} / \mathrm{min} / \mathrm{kg}$ in female triathletes. In terms of echocardiographic measurement we can expect concentric remodelling /concentric hypertrophy. Concentric hypertrophy can be expected up to $20 \%$ in healthy female triathletes. Valve dysfunctions are possible but in our cohort rare.

We have not found negative long term effects on cardiac structures as proposed for "exercised-induced cardiac fatigue" [35]. In our cohort we have triathletes with a mean time of participation in triathlon competitions of 5.4 years (non-Elite) and 7.8 years (elite). The longest time participating in triathlon competitions was 32 years.

Sudden cardiac death in female athletes is rare $(20 \mathrm{x}$ less frequently as in men) [36]. The known problem of arrhythmias in the aged athletes also more often occurs in the male athlete [37].

Adequate screening of triathletes for possible silent diseases based on the different cardiologic diagnostic tools should be considered [38-40]. With regard to our data, we can suggest that long-term adverse cardiac effects of endurance sport in female triathletes seem to be rare [41]. The positive impact of physical activity at the recreational level is not up for discussion [42, 43].

\section{References}

[1] Triathlon, U. Demographics, Triathlon participation, growth trends and demographics. 2013 (updated April 2013); Available from: http://www.usatriathlon.org/about-multisport/demographics. aspx.

[2] La Gerche, A., A.T. Burns, D.J. Mooney, W.J. Inder, A.J. Taylor, J. Bogaert, A.I. MacIsaac, H. Heidbüchel and D.L. Prior, Exercise-induced right ventricular dysfunction and structural remodelling in endurance athletes. European heart journal, 2012. 33(8): p. 998-1006.

[3] Douglas, P.S., M.L. O'Toole, W.D. Hiller, K. Hackney and N. Reichek, Cardiac fatigue after prolonged exercise. Circulation, 1987. 76(6): p. 1206-13.

[4] Harris, K.M., J.T. Henry, E. Rohman, T.S. Haas and B.J. Maron, Sudden death during the triathlon. Jama, 2010. 303(13): p. 1255-7.

[5] Suriano, R. and D. Bishop, Physiological attributes of triathletes. J Sci Med Sport, 2010. 13(3): p. 340-7.

[6] Sleivert, G.G. and D.S. Rowlands, Physical and physiological factors associated with success in the triathlon. Sports Med, 1996. 22(1): p. 8-18.

[7] O'Toole, M.L. and P.S. Douglas, Applied physiology of triathlon. Sports Med, 1995. 19(4): p. 251-67.

[8] O'Toole, M.L., D.B. Hiller, L.O. Crosby and P.S. Douglas, The ultraendurance triathlete: a physiological profile. Med Sci Sports Exerc, 1987. 19(1): p. 45-50.

[9] O'Toole, M.L., P.S. Douglas and W.D. Hiller, Lactate, oxygen uptake, and cycling performance in triathletes. Int $\mathrm{J}$ Sports Med, 1989. 10(6): p. 413-8.

[10] Kohrt, W.M., D.W. Morgan, B. Bates and J.S. Skinner, Physiological responses of triathletes to maximal swimming, cycling, and running. Med Sci Sports Exerc, 1987. 19(1): p. $51-5$. 
[11] Butts, N.K., B.A. Henry and D. McLean, Correlations between $\mathrm{VO} 2 \mathrm{max}$ and performance times of recreational triathletes. J Sports Med Phys Fitness, 1991. 31(3): p. $339-44$.

[12] Sleivert, G.G. and H.A. Wenger, Physiological predictors of short-course triathlon performance. Med Sci Sports Exerc, 1993. 25(7): p. 871-6.

[13] Schabort, E.J., S.C. Killian, A. St Clair Gibson, J.A. Hawley and T.D. Noakes, Prediction of triathlon race time from laboratory testing in national triathletes. Med Sci Sports Exerc, 2000. 32(4): p. 844-9.

[14] Douglas, P.S., M.L. O'Toole, S.E. Katz, G.S. Ginsburg, W.D. Hiller and R.H. Laird, Left ventricular hypertrophy in athletes. Am J Cardiol, 1997. 80(10): p. 1384-8.

[15] Lang, R.M., M. Bierig, R.B. Devereux, F.A. Flachskampf, E. Foster, P.A. Pellikka, M.H. Picard, M.J. Roman, J. Seward and J. Shanewise, Recommendations for chamber quantification. European Journal of Echocardiography, 2006 7(2): p. 79-108.

[16] Laurenson, N.M., K.Y. Fulcher and P. Korkia, Physiological characteristics of elite and club level female triathletes during running. Int J Sports Med, 1993. 14(8): p. 455-9.

[17] Atchley, A.E., Jr. and P.S. Douglas, Left ventricular hypertrophy in athletes: morphologic features and clinical correlates. Cardiol Clin, 2007. 25(3): p. 371-82, v.

[18] George, K.P., L.A. Wolfe and G.W. Burggraf, The 'athletic heart syndrome'. A critical review. Sports Med, 1991. 11(5): p. $300-30$

[19] Dickhuth, H., A. Hipp, A. Niess, K. Röcker, F. Mayer and T. Horstmann, Differenzialdiagnostik der physiologischen Herzhypertrophie (Sportherz). DEUTSCHE ZEITSCHRIFT FÜR SPORTMEDIZIN, 2001. 52(6): p. 205-210.

[20] Henschen, S., Skilanglauf und Skiwettlauf. Eine medizinische Sportstudie. Mitt Med Klin Upsala, 1899:. 2:: p. 74.

[21] Whyte, G.P., K. George, A. Nevill, R. Shave, S. Sharma and W.J. McKenna, Left ventricular morphology and function in female athletes: a meta-analysis. Int J Sports Med, 2004. 25(5): p. 380-3

[22] Douglas, P.S., Cardiac considerations in the triathlete. Med Sci Sports Exerc, 1989. 21(5 Suppl): p. S214-8.

[23] Pelliccia, A., B.J. Maron, A. Spataro, M.A. Proschan and P. Spirito, The upper limit of physiologic cardiac hypertrophy in highly trained elite athletes. N Engl J Med, 1991. 324(5): p. 295-301.

[24] Pluim, B.M., A.H. Zwinderman, A. van der Laarse and E.E. van der Wall, The athlete's heart a meta-analysis of cardiac structure and function. Circulation, 2000. 101(3): p. 336-344.

[25] Fagard, R., A. Aubert, J. Staessen, E.V. Eynde, L. Vanhees and A. Amery, Cardiac structure and function in cyclists and runners. Comparative echocardiographic study. Br Heart J, 1984. 52(2): p. 124-9.

[26] Hoogsteen, J., A. Hoogeveen, H. Schaffers, P.F. Wijn and E.E. van der Wall, Left atrial and ventricular dimensions in highly trained cyclists. Int J Cardiovasc Imaging, 2003. 19(3): p. 211-7.
[27] Marijon, E., M. Tafflet, D.S. Celermajer, F. Dumas, M.C. Perier, H. Mustafic, J.F. Toussaint, M. Desnos, M. Rieu, N. Benameur, J.Y. Le Heuzey, J.P. Empana, and X. Jouven, Sports-related sudden death in the general population. Circulation, 2011. 124(6): p. 672-81.

[28] Solberg, E.E., F. Gjertsen, E. Haugstad and L. Kolsrud, Sudden death in sports among young adults in Norway. Eur J Cardiovasc Prev Rehabil, 2010. 17(3): p. 337-41.

[29] Maron, B.J., P.D. Thompson, M.J. Ackerman, G. Balady, S. Berger, D. Cohen, R. Dimeff, P.S. Douglas, D.W. Glover and A.M. Hutter, Recommendations and Considerations Related to Preparticipation Screening for Cardiovascular Abnormalities in Competitive Athletes: 2007 Update A Scientific Statement From the American Heart Association Council on Nutrition, Physical Activity, and Metabolism: Endorsed by the American College of Cardiology Foundation. Circulation, 2007. 115(12): p. 1643-1655.

[30] Corrado, D., C. Basso, G. Rizzoli, M. Schiavon and G. Thiene, Does sports activity enhance the risk of sudden death in adolescents and young adults? J Am Coll Cardiol, 2003. 42(11): p. 1959-63.

[31] Rifai, N., P.S. Douglas, M. O'Toole, E. Rimm and G.S Ginsburg, Cardiac troponin $\mathrm{T}$ and I, echocardiographic [correction of electrocardiographic] wall motion analyses, and ejection fractions in athletes participating in the Hawaii Ironman Triathlon. Am J Cardiol, 1999. 83(7): p. 1085-9.

[32] Hue, O., Prediction of drafted-triathlon race time from submaximal laboratory testing in elite triathletes. Can J Appl Physiol, 2003. 28(4): p. 547-60.

[33] Bunc, V., J. Heller, J. Horcic and J. Novotny, Physiological profile of best Czech male and female young triathletes. J Sports Med Phys Fitness, 1996. 36(4): p. 265-70.

[34] O'Keefe, J.H., R.P. Harshal, C.J. Lavie, A. Magalski, R.A. Vogel and P.A. McCiiough, Potential Adverse Cardiovascular Effects From Excessive Endurance Exercise. Mayo Clin Proc., 2012. 87(6): p. 587-595.

[35] Oxborough, D., K. Birch, R. Shave and K. George, "Exercise-induced cardiac fatigue"--a review of the echocardiographic literature. Echocardiography, 2010. 27(9): p. $1130-40$.

[36] Marijon, E., W. Bougouin, M.C. Perier, D.S. Celermajer and $X$. Jouven, Incidence of sports-related sudden death in France by specific sports and sex. Jama, 2013. 310(6): p. 642-3.

[37] Andersen, K., B. Farahmand, A. Ahlbom, C. Held, S. Ljunghall, K. Michaelsson and J. Sundstrom, Risk of arrhythmias in 52755 long-distance cross-country skiers: a cohort study. Eur Heart J, 2013

[38] Leischik, R., B. Dworrak, H. Littwitz and H. Gulker, Prognostic significance of exercise stress echocardiography in 3329 outpatients (5-year longitudinal study). Int J Cardiol, 2007. 119(3): p. 297-305.

[39] Leischik, R. Ugly duckling or Nosferatu ? - marathon running and cardiovascular function How to screen the athletes? 2014; $\quad$ Available http://eurheartj.oxfordjournals.org/content/early/2014/01/08/ eurheartj.eht502/reply\#ehj_el_2040. 
[40] La Gerche, A., A.L. Baggish, J. Knuuti, D.L. Prior, S. Sharma, H. Heidbuchel and P.D. Thompson, Cardiac imaging and stress testing asymptomatic athletes to identify those at risk of sudden cardiac death. JACC Cardiovasc Imaging, 2013. 6(9): p. 993-1007.

[41] Pelliccia, A., N. Kinoshita, C. Pisicchio, F. Quattrini, F.M. DiPaolo, R. Ciardo, B. Di Giacinto, E. Guerra, E. De Blasiis, M. Casasco, F. Culasso and B.J. Maron, Long-Term Clinical Consequences of Intense, Uninterrupted Endurance Training in Olympic Athletes. Journal of the American College of Cardiology, 2010. 55(15): p. 1619-1625.

[42] Organisation, W.H. Global Health Risks. 2009; Page 17,18, : Available from:

http://www.who.int/healthinfo/global_burden_disease/Globa 1HealthRisks_report_full.pdf.

[43] Warburton, D.E., C.W. Nicol and S.S. Bredin, Health benefits of physical activity: the evidence. Cmaj, 2006. 174(6): p. 801-9. 